\title{
18Fluorodeoxyglucose Positron Emission Tomography Studies in Presumed Alzheimer Cases, Including 13 Serial Scans
}

\author{
E.G. McGeer, R.P. Peppard, P.L. McGeer, H. Tuokko, D. Crockett, R. Parks, H. Akiyama, \\ D.B. Calne, B.L. Beattie and R. Harrop
}

\begin{abstract}
Positron emission tomographic (PET) data on local cerebral metabolic rates for glucose (LCMR) are reported for 32 regions of interest (ROI)s in cross-sectional studies on 57 patients with clinically diagnosed Alzheimer's disease (AD) and 20 neurologically normal controls, and in serial studies on 13 of the AD cases, including a familial, young-onset case where the diagnosis has been confirmed at autopsy. Extensive psychological testing was done on all the AD cases. Almost all cortical regions showed a significant decline in LCMR with age in the control subjects. There were the expected cortical metabolic deficits in AD and the serial studies showed a general increase in such deficits over time in 12 of the 13 cases. The regions showing the greatest declines with time in serial studies are the same as those showing the most severe deficiencies in cross-sectional studies. The young-onset case did not show a greater rate of metabolic decline than many of the older cases studied. Results on individual psychological tests tended to correlate with metabolic rates in multiple, rather than single, cortical regions, suggesting intact neuronal networks are required for good performance. The correlations with cortical metabolic activity found were of a sign indicating that the higher the metabolic rates and the better the left:right asymmetry index, the better was the performance.
\end{abstract}

RÉSUMÉ: Tomographie par émission de positrons utilisant le ${ }^{18}$ F-fluorodeoxyglucose chez des cas présumément atteints de la maladie d'Alzheimer, dont 13 scans sériés Nous rapportons les données sur les taux métaboliques cérébraux locaux d'utilisation du glucose (TMCL) déterminés au moyen de la tomographie par émission de positrons (PET) dans 32 régions d'intérêt, en étude transversale chez 57 patients avec un diagnostic clinique de maladie d'Alzheimer (MA) et 20 contrôles normaux au point de vue neurologique, en étude sériée chez 13 cas de MA, incluant un cas de MA familiale, à début précoce, où le diagnostic a été confirmé à l'autopsie. Tous les cas de MA ont été soumis à une évaluation psychologique poussée. Il existait une diminution significative du TMCL avec l'âge chez les contrôles dans presque toutes les régions corticales. Les déficits métaboliques corticaux auxquels on s'attendait étaient présents dans la MA et les études sériées ont montré un accroissement général de ces déficits avec le temps chez 12 des 13 sujets. Les régions manifestant les plus hauts taux de progression des déficits avec le temps dans les études sériées sont les mêmes que celles manifestant les déficits les plus sévères dans les études transversales. Le cas à début précoce ne montrait pas une diminution plus rapide du taux métabolique que plusieurs des cas plus âgés qui ont été étudiés. Les résultats des épreuves psychologiques individuelles tendaient à être en corrélation avec les taux métaboliques dans plusieurs régions corticales plutôt que dans une seule, suggérant que des réseaux neuronaux intacts sont requis pour fournir un bon rendement. Les corrélations avec l'activité métabolique corticale indiquent que plus les taux métaboliques étaient élevés et meilleur était l'index d'asymétrie gauche : droite, meilleur était le rendement.

Can. J. Neurol. Sci. 1990; 17:1-11

It is well established that patients with clinically diagnosed Alzheimer disease (AD) show decreased cortical metabolic rates in positron emission tomographic (PET) scans using 18F-fluorodeoxyglucose. ' Although the symptoms of AD are progressive, relatively few reports exist of serial PET scans on patients to document the course of the metabolic disorder and to determine whether relationships exist between psychological deficits and local cerebral metabolic rates for glucose (LCMR). This paper is an attempt to determine: (i) whether there is an increasing metabolic deficit with time which is more or less uniform from case to case or from region to region of brain; and (ii) if the LCMRs (or changes in LCMRs over time) correlate with results of psychological tests (or change in performance). We were particularly interested in whether relatively young AD cases would

From the Kinsmen Laboratory of Neurological Research Department of Psychiatry (E.G.M., P.L.M., R.P., H.A.); Division of Neurology, Department of Medicine (R.P.P., D.B.C.); Department of Psychology, University Hospital (H.T.); Division of Psychology, Department of Psychiatry (D.C., R.P.); Department of Medicine, University of B.C. (B.L.B.), Vancouver, and School of Computer Science, Simon Fraser University (R.H.), Burnaby, British Columbia

Received June 5, 1989. Accepted in final form September 30, 1989

Reprint requests to: Dr. Edith McGeer, 2255 Wesbrook Mall, University of B.C., Vancouver, British Columbia, Canada V6T 1W5 
Table 1: Sex, Age and Other Data on Cases Given Repeat Scans

\begin{tabular}{|c|c|c|c|c|c|c|c|}
\hline \multirow[b]{2}{*}{ Case No. } & \multirow{2}{*}{$\begin{array}{l}\text { Age at } \\
\text { First } \\
\text { Scan }\end{array}$} & \multirow[b]{2}{*}{ Sex } & \multirow{2}{*}{$\begin{array}{c}\text { Months } \\
\text { between } \\
\text { Scans }\end{array}$} & \multicolumn{2}{|c|}{ Average on Psychological Tests ${ }^{* *}$} & \multicolumn{2}{|c|}{$\begin{array}{c}\text { Months between } \\
\text { Psychological Testing }\end{array}$} \\
\hline & & & & 1st Testing & 2nd Testing & And Scans & Two Tests \\
\hline $1^{*}$ & 45 & $\mathbf{M}$ & 11.5 & $68.3 \pm 31.3$ & $55.4 \pm 40.3$ & $0.03,0.03$ & 11.5 \\
\hline 2 & 58 & M & 11.0 & $64.8 \pm 28.9$ & $59.3 \pm 28.7$ & $2.6,1.6$ & 12 \\
\hline 3 & 59 & $\mathrm{~F}$ & 16.4 & $61.7 \pm 33.7$ & $26.8 \pm 26.5$ & 2,5 & 13.3 \\
\hline 4 & 64 & $\mathrm{~F}$ & 12.0 & $52.1 \pm 28.0$ & $46.8 \pm 34.5$ & $0.2,0.2$ & 12 \\
\hline 5 & 65 & M & 17.2 & $58.3 \pm 30.8$ & $38.2 \pm 32.8$ & $3,0.2$ & 20.4 \\
\hline 6 & 65 & $\mathbf{M}$ & 11.3 & $72.6 \pm 25.0$ & $59.8 \pm 32.5$ & $3,0.2$ & 9.5 \\
\hline 7 & 66 & $\mathrm{~F}$ & 13.5 & $72.3 \pm 24.2$ & $69.6 \pm 26.0$ & $2.4,2.4$ & 13.5 \\
\hline $8^{*}$ & 68 & $\mathrm{~F}$ & 11.5 & $58.4 \pm 28.0$ & $48.7 \pm 30.6$ & $0.1,0.8$ & 13.3 \\
\hline 9 & 69 & $\mathrm{~F}$ & 13.0 & $52.6 \pm 35.1$ & $43.8 \pm 36.5$ & $1.6,1.5$ & 14.2 \\
\hline 10 & 70 & $\mathrm{~F}$ & 13.3 & $69.3 \pm 26.2$ & $61.2 \pm 31.2$ & $2,0.8$ & 13.5 \\
\hline 11 & 75 & $\mathrm{~F}$ & 19.0 & $74.8 \pm 23.4$ & $53: 2 \pm 35.2$ & $1.5,0.3$ & 21 \\
\hline 12 & 81 & $\mathrm{~F}$ & 21.2 & $60.7 \pm 26.4$ & $46.0 \pm 29.0$ & $3,0.03$ & 24.2 \\
\hline 13 & 81 & $\mathrm{~F}$ & 15.7 & $69.0 \pm 27.4$ & $61.0 \pm 28.9$ & $2,0.5$ & 15.2 \\
\hline
\end{tabular}

${ }^{*}$ Autopsy-confirmed

${ }^{* *}$ The average on psychological testing is the mean percentage obtained when the performance on each test is expressed as a percent of the total possible. Clearly, this is a crude measure but is presented simply to indicate that there was some deterioration in each case and, as indicated by the standard deviations of the means, the performance on the various tests (see Table 2 for names of tests) by any individual varied widely.

show faster declines in LCMR and/or psychological tests than would older cases. We report PET scan data from a series of 57 cases with clinically diagnosed $A D$, including 13 who had serial scans. Among those serially scanned was a case of young-onset

Table 2: Psychological Tests Used with Mean Scores ( \pm S.D.M.) (as Percent of Total Possible Score) of the AD Group Receiving Repeated Scans plus Testing (numbers are used for convenience of later referencing)

\begin{tabular}{|c|c|c|}
\hline Test & $\begin{array}{c}\text { First } \\
\text { Test }\end{array}$ & $\begin{array}{c}\text { Second } \\
\text { Test }\end{array}$ \\
\hline \multicolumn{3}{|l|}{ MAS } \\
\hline 1. Social behavior & $100 \pm 0$ & $951 \pm 12.6$ \\
\hline 2. Auditory receptive language & $80.3 \pm 10.3$ & $78.6 \pm 14.7$ \\
\hline 3. Visual receptive language & $98.1 \pm 13.4$ & $87.5 \pm 28.9$ \\
\hline 4. Mental status & $72.3 \pm 28.6$ & $43.8 \pm 33.3$ \\
\hline 5. Orientation & $86.9 \pm 8.5$ & $60.6 \pm 24.3$ \\
\hline 6. Mood & $50.5 \pm 33.4$ & $45.0 \pm 39.2$ \\
\hline 7. Expressive language & $92.3 \pm 20.0$ & $71.8 \pm 30.0$ \\
\hline \multicolumn{3}{|l|}{ WAIS } \\
\hline 9. Information & $35.2 \pm 14.3$ & $23.9 \pm 13.9$ \\
\hline 10. Digit span & $43.3 \pm 15.7$ & $32.8 \pm 18.7$ \\
\hline 11. Similarities & $42.9 \pm 14.7$ & $33.2 \pm 14.5$ \\
\hline 12. Block design & $37.2 \pm 18.0$ & $23.1 \pm 16.3$ \\
\hline 13. Vocabulary & $67.5 \pm 23.2$ & $59.5 \pm 25.2$ \\
\hline 14. Digit symbol & $70.8 \pm 19.8$ & $43.0 \pm 22.6$ \\
\hline \multicolumn{3}{|l|}{ LURIA-NEBRASKA (Designs) } \\
\hline 16. Immediate recall & $47.7 \pm 19.2$ & $38.5 \pm 23.7$ \\
\hline 17. Reproduction & $98.5 \pm 5.5$ & $98.5 \pm 5.5$ \\
\hline 18. Delayed recall & $49.2 \pm 31.2$ & $43.1 \pm 30.4$ \\
\hline \multicolumn{2}{|l|}{ BUSCHKE CUED RECALL } & $26.8 \pm 18.0$ \\
\hline 20. Immediate recall & $31.2 \pm 14.3$ & $16.0 \pm 15.4$ \\
\hline 21. Retrieval & $43.2 \pm 27.6$ & $17.3 \pm 16.7$ \\
\hline 22. Acquisition & $77.5 \pm 32.5$ & $49.9 \pm 39.4$ \\
\hline $\begin{array}{l}\text { 23. Retention } \\
\text { TAPPING }\end{array}$ & $75.7 \pm 32.5$ & $45.5 \pm 41.3$ \\
\hline 24. Right hand & $71.3 \pm 15.7$ & $70.9 \pm 20.2$ \\
\hline $\begin{array}{l}\text { 25. Left hand } \\
\text { GRIP }\end{array}$ & $65.7 \pm 15.0$ & $61.7 \pm 18.9$ \\
\hline 26. Right hand & $48.8 \pm 18.5$ & $40.0 \pm 21.4$ \\
\hline 27. Left hand & $46.4 \pm 18.4$ & $34.6 \pm 22.9$ \\
\hline
\end{tabular}

familial Alzheimer's disease and this case, as well as 7 other, older-onset cases, have been confirmed at autopsy. Detailed assessment involving 27 psychological tests was carried out. Although the serial scanned cases generally showed increasing metabolic and psychological deficits, correlational analysis indicated that performance on any individual psychological test probably depended on the metabolic integrity of a cortical network of neuronal activity. ${ }^{2}$

\section{Patients and Methods}

Cerebral glucose metabolism was studied using positron emission tomography (PET) and 18F-2-fluoro-2-deoxyglucose (FDG) in 57 patients with clinically diagnosed dementia of the Alzheimer type (AD), including one familial case (FAD) in his forties, and 20 neurologically normal controls; 8 of the dementia cases, including the FAD case, have subsequently come to autopsy and had the diagnosis confirmed. The other AD cases all had symptoms which met the NINCDS-ADRDA criteria ${ }^{3}$ for diagnosis of probable or possible Alzheimer's disease. All PETscanned cases had extensive psychological testing and CT and/or magnetic resonance imaging (MRI) scans to rule out the presence of significant multi-infarcts. The PET-scanned controls were largely recruited from spouses of patients appearing at the Movement Disorder or Alzheimer Clinics of the University Hospital, UBC site, or from a community center for the elderly. Twelve AD cases and the FAD case had repeat PET scans at an average interval of 15 months, as well as repeat psychological testing (Table 1). The psychological tests used are listed in Table 2. Extensive psychological and genetic data on the FAD case, where 12 individuals in four generations of the family had been affected, have already been published. ${ }^{4}$ The "normal" values in the psychological test battery are based on testing large groups of elderly volunteers recruited from community activity centers. 5,6

The PET scan protocol has been described previously. ${ }^{7}$ The method of analysis involved choosing regions of interest (ROI)s of fixed size and shape placed along the cortical mantle on each successive slice, following the atlas of Hanaway et al. 8 Adjust- 
Table 3: Change per Year in Ln(LCMR) in Controls as Indicated by Correlations for Activity vs Age Significant at $p<0.05$ or Better*

\begin{tabular}{lclllc}
\hline \hline Region & Change/Yr & \multicolumn{2}{l}{ Region } & Change/Yr & \multicolumn{2}{l}{ Region } & Change/Yr \\
\hline LSF & -0.00484 & LAG & -0.00414 & LmO & n.s. \\
RSF & -0.00545 & RAG & -0.00414 & RmO & n.s. \\
LMF & -00.439 & LSP & -0.00546 & LCA & -0.00248 \\
RMF & -0.00463 & RSP & -0.00425 & RCA & -0.00324 \\
LOF & -0.00473 & LST & -0.00484 & LPU & -0.00306 \\
ROF & -0.0086 & RST & -0.00462 & RPU & -0.00296 \\
LPC & -0.00495 & LMT & -0.00292 & LTH & n.s. \\
RPC & -0.00468 & RMT & n.s. & RTH & n.s. \\
LSM & -0.00522 & LIT & -0.00406 & LCE & n.s. \\
RSM & -0.00462 & RIT & n.s. & RCE & n.s. \\
& & LmT & -0.00304 & & \\
& & RmT & -0.00237 & & \\
\hline
\end{tabular}

${ }^{*}$ Abbreviations are as in Figure 1 except initial $\mathrm{L}$ or $\mathrm{R}$ indicates left or right hemisphere. n.s. Correlation not significant.

ments in placement were occasionally made according to apparent variations in head positioning from the orbital-meatal plane (flexion-extension, lateral flexion and rotation). For large cortical areas and the cerebellum, ROIs from multiple slices were averaged. This was done by calculating the volume weighted mean of the activity of the appropriate ROI from each slice. For example, the LCMR for the left superior frontal area was calculated from the mean activity of $6 \mathrm{ROIs}$ from consecutive slices. In this way, LCMR values were obtained for 32 areas (see caption to Figure 1 for definition). LCMR values were calculated from PET scan and blood data using literature values for the lumped constant. ${ }^{9}$ Some influence of cortical atrophy on these data cannot be ruled out but it has been previously shown by us 10 and others ( $\mathrm{cf}^{\mathrm{ll}}$ ) that such atrophy is not the determining factor in the differences in LCMR between AD cases and elderly controls.

A natural logarithmic transformation of each LCMR was performed to reduce the dependence of the standard deviation on the mean result for each $\mathrm{ROI}$. We also calculated from the LCMR data for each scan the ratios $(\mathrm{F}-\mathrm{P}) /(\mathrm{F}+\mathrm{P})$ and $(\mathrm{F}-\mathrm{T}) /(\mathrm{F}+\mathrm{T})$, using $\mathrm{F}$ (frontal) and $\mathrm{P}$ (parietal) as the mean LCMR for each case in 6 regions (left and right superior frontal, midfrontal and orbitofrontal, and left and right angular gyrus, supramarginal and superior parietal, respectively), and T (temporal) as the mean LCMR in 8 regions (left and right superior temporal, middle temporal, inferior temporal and medial temporal). These ratios were desired because Jagust et al ${ }^{12}$ suggested that changes in them over time would correlate with changes in various psychological tests.

Analyses of variance (ANOVA) were used to test for significant effects of age, sex or diagnostic category, followed where
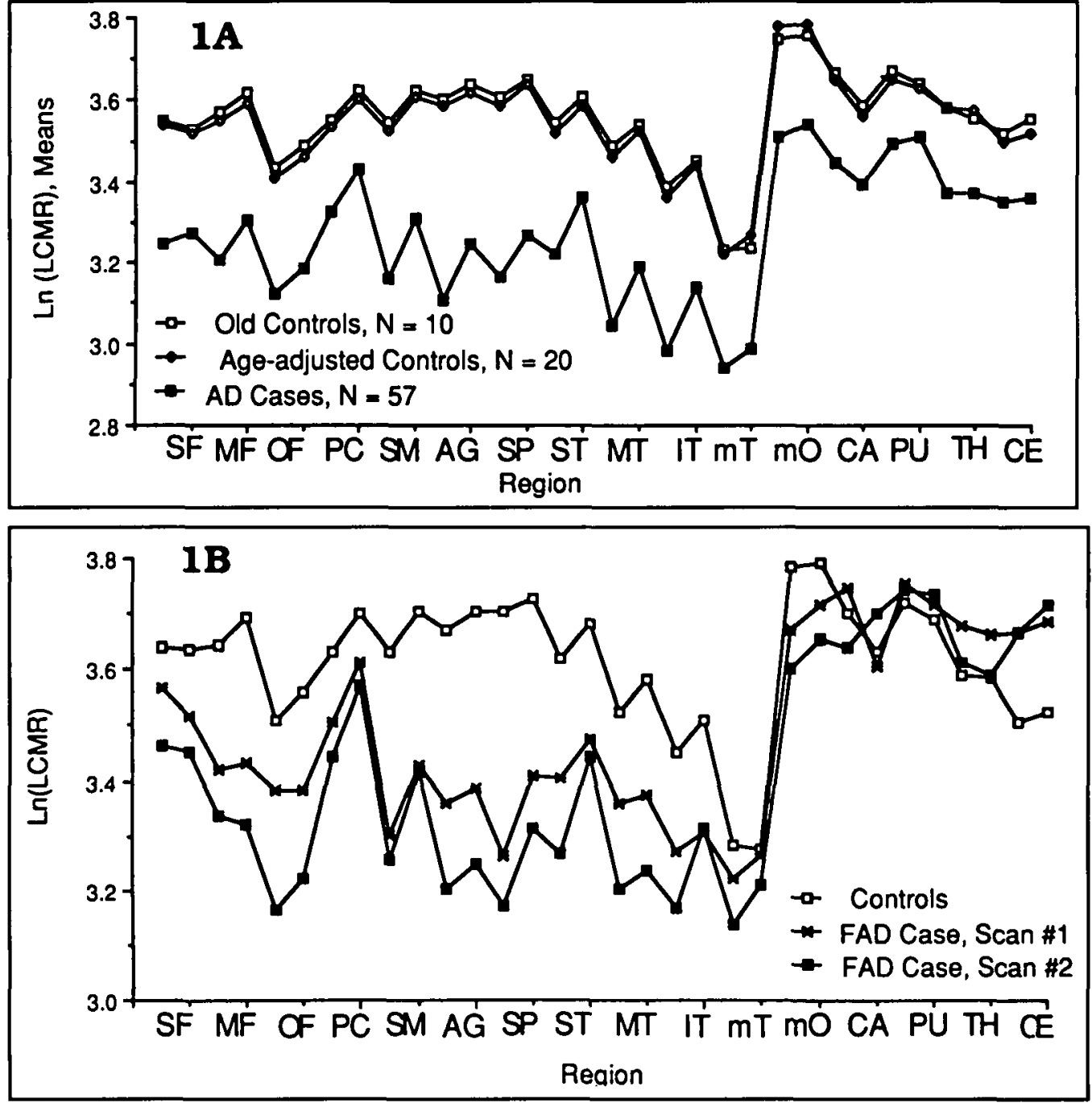

Figure 1 - Plot of $\operatorname{Ln}(L M C R)$ for 32 ROIs. The left ROI is given in each case before its right homolog, with the areas being: $S F$, superior frontal; $M F$, mid. frontal; $O F$, orbitofrontal: $P C$, peri-central: $S M$, supramarginal; $A G$, angular: $S P$, superior parietal; ST, superior temporal; $M T$, middle temporal; IT, inferior temporal: $m T$. medial temporal; mO. medial occipital; $C A$, caudate; $P U$, putamen; $T H$, thalamus; and CE, cerebellum. A) Data for means obtained for 3 groups: one composed of 57 AD cases: one of 10 age-matched controls; and the third of 20 controls where the data on each control were adjusted before averaging to the mean age of the $A D$ group by using the lines of regression determined for each region from the control data (Table 3). The mean for the $A D$ group is significantly lower than both control means at $p<0.001$ in all regions except the left cerebellum and right putamen where the differences are significant at $p<$ 0.01 . B) Plot of data from two scans done approximately 1 year apart on an autopsyproven case of familial Alzheimer's disease (FAD), aged 45 and 46 at the times of the scans, as well as the means for an age-matched group of 20 neurologically normal controls. The FAD case died at age 48. 


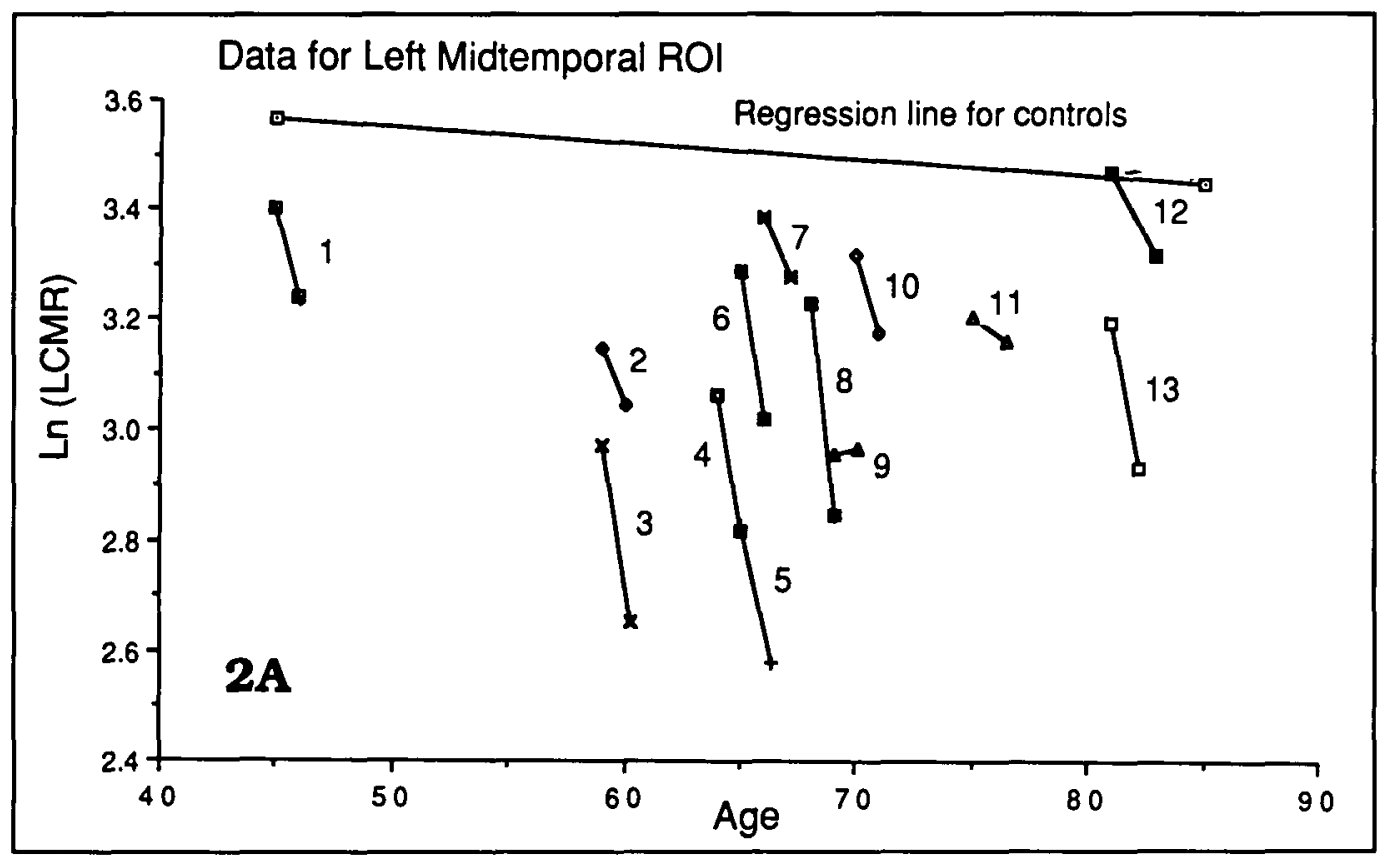

Figure 2:-A) $\operatorname{Ln}(L C M R)$ in the left middle temporal ROI as a function of age in a group of 20 controls (highly significant regression line) and 13 $A D$ cases who received repeat scans. The numbers by each line are the case numbers as given in Table I. The literature on repeat scans in controls indicates, as does this Figure, very little change/year in LCMR. B) Mean change per year for each case in $\operatorname{Ln}(L C M R)$ for the 32 ROIs plotted against the change in the 27 psychological tests scored as a fraction of maximum score achievable in each test. In both instances, a positive number indicates a decrement in metabolic rate or function. Standard deviations are indicated for the mean changes in Ln(LCMR). The case numbers are as given in Table 1 .

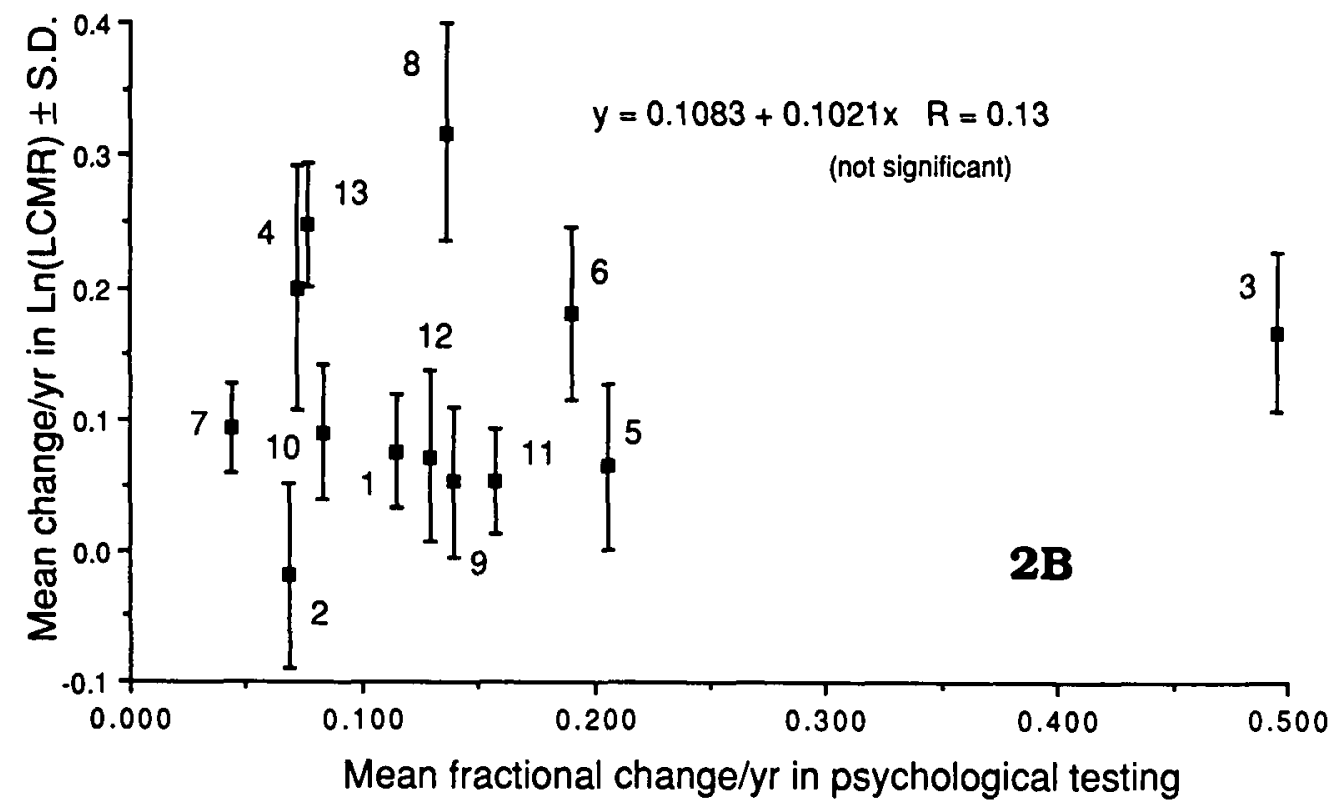

indicated by regression analysis or the student $t$ test. All means reported are given plus or minus the standard deviation.

For the serially-scanned cases, a rate of change of $\mathrm{Ln}(\mathrm{LCMR})$ in each area was calculated by taking the difference between the first and second scans and dividing it by the fractional year between the scans. A similar approach was used to calculate a rate of change in each psychological test; in this instance the change/year was expressed as a percentage of the maximum score obtainable in the given test. $5.6,13$

Correlations among the PET scan and psychological test data were carried out as follows:

(i) The results in individual psychological tests and the Ln(LCMR) for each region were correlated by Spearman's method for all AD cases.

(ii) The results in individual psychological tests and the asymmetry index of each ROI, calculated as $2\left[\mathrm{LCMR}_{\mathrm{R}^{-}}\right.$
$\left.\mathrm{LCMR}_{\mathrm{L}}\right] /\left[\mathrm{LCMR}_{\mathrm{R}}+\mathrm{LCMR}_{\mathrm{L}}\right]$, were correlated by Spearman's method.

(iii) The rate of change in $\mathrm{Ln}(\mathrm{LCMR})$ in each ROI and the rate of change in each psychological test in the serially scanned group were analyzed both by Spearman's method and by multiple factor analysis; only the results of the former are reported in detail since the two methods gave highly comparable results.

(iv) Spearman correlation coefficients were also calculated for the difference between the individual first and second psychological test scores (Table 1) and the difference in each of the ratios $(\mathrm{F}-\mathrm{P}) /(\mathrm{F}+\mathrm{P})$ and $(\mathrm{F}-\mathrm{T}) /(\mathrm{F}+\mathrm{T})$ for the first and second scans.

(iv) For the serially scanned cases, Pearson correlations were done for the first and second psychological test results and the first and second PET Ln(LCMR) for each ROI. 


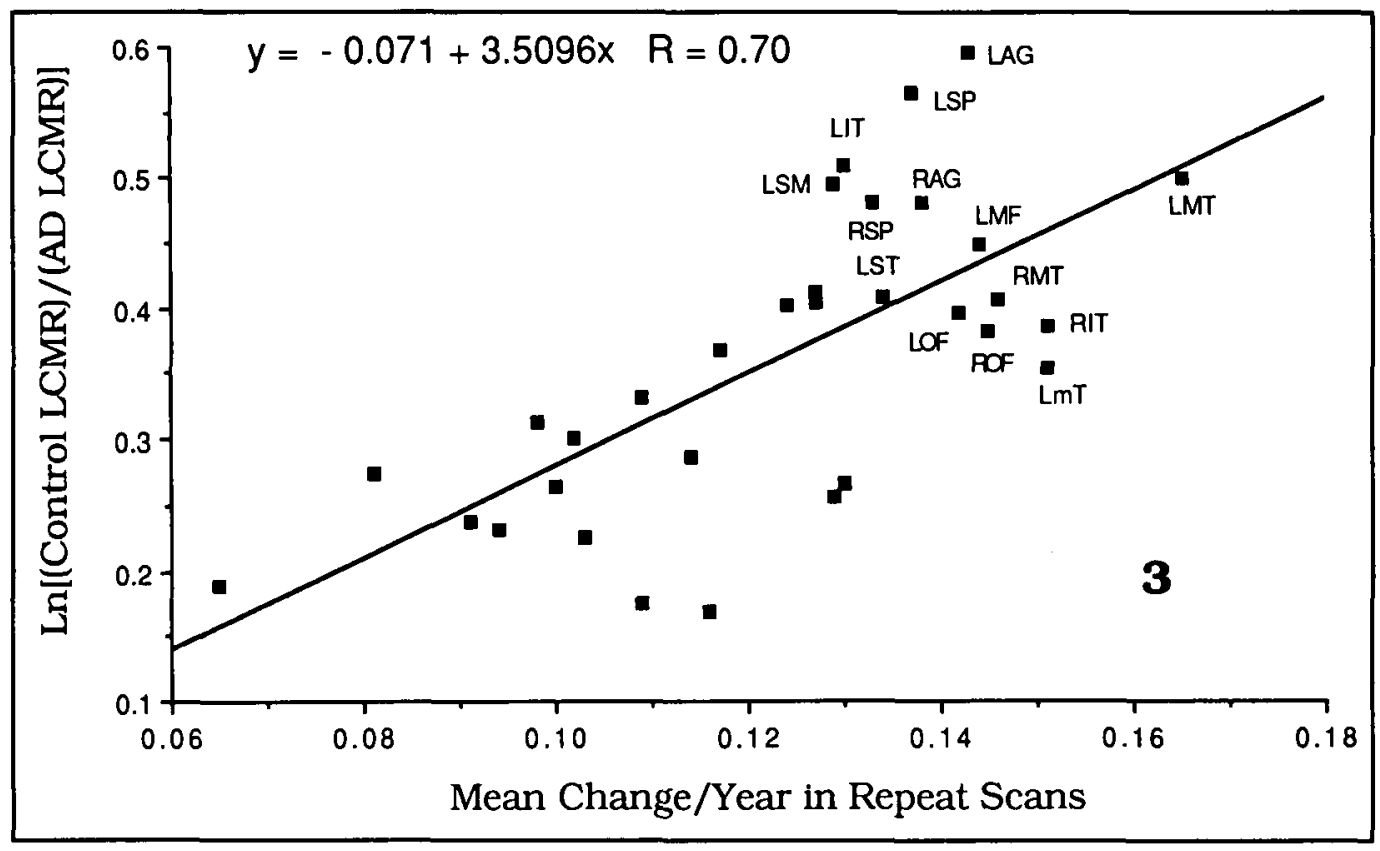

Figure 3:- Mean change per year for each region in the Ln $(L C M R)$, calculated from the repeat scans on $13 A D$ cases, plotted against the Ln/(control LCMR)/(AD $L C M R)$, i.e. the difference between the $\operatorname{Ln}(L C M R)$ for each region for the age. adjusted control and $A D$ groups (cf Figure IA). As indicated, there is a highly significant correlation. The identity of the ROLs showing the greatest changes are indicated by abbreviations as used in Figure I cxcept that the initial $L$ or $R$ refers to the left and right side. respectively.

Where these were significant, an "expected value" for the second test or scan was calculated from the first result and the appropriate correlation equation. The differences between the "expected values" and the actual scores in psychological tests or metabolic data were then compared by Spearman's method. Detailed results are not reported since significant correlations were only found for the Wechsler Adult Intelligence Scale (WAIS) Similarities (test 11, Table 2) and the left SF, PC, ST and the right $\mathrm{AG}, \mathrm{MT}$ and $\mathrm{TH}$; all were positive (see caption to Figure 1 for definition of regional abbreviations).

\section{RESULTS}

An ANOVA indicated no significant effect of sex in either the $A D$ or control group; there was, however, a significant effect of age in the controls although not in the AD cases. A significant, if slight, decrease with age was found in the controls in all ROIs except the left and right cerebellum, thalamus and medial occipital area, and the right midtemporal region (Figure $2 \mathrm{~A}$, Table 3). Since the average age for the total group of 20 controls was $49.3 \pm 9.88$ (mean + S.D.), while that for the AD group was $67.77 \pm 8.80$, the individual control data for each region where a significant age effect was found were adjusted to age 67.77 , using the equations indicated in Table 3 , and new means calculated (controls - age adjusted). Unadjusted means were also calculated for the 10 controls who were age-matched $(67.2 \pm 9.88)$ to the AD cases (controls - age matched).

A plot of the mean metabolic rates in the AD and control groups in the 32 selected regions of brain is shown in Figure 1A. Although the figure indicates that the absolute values in most ROls were lower on the left side of the brain than on the right, an ANOVA indicated that this left/right difference was not significant for any group. It is clear from Figure $1 \mathrm{~A}$ that the ageadjusted control values were almost identical with those for the age-matched controls, which tended to validate the method used for age adjustment. The AD group had generally lower metabolic rates in all the regions examined although the difference between $\mathrm{AD}$ and control groups varied from region to region.

Figure 1B gives the $\operatorname{Ln}(\mathrm{LCMR})$ found in serial scans on the case of FAD. In this case the total control data unadjusted for age are illustrated since this FAD case was only $44-46$ at the time of the scans. Many cortical regions clearly showed a loss in Ln(LCMR) between the first and second scans. An ANOVA failed to indicate a significant difference between the scans if all 32 regions were considered $[F(1,61) 3.073, p=0.085]$, but the difference was significant if the subcortical regions were omitted $[F(1,46) 5.39, p=0.025]$. This was also true in all but one of the 13 cases who had repeat scans. There were marked changes in most regions but the slope varied considerably from case to case as exemplified in Figure $2 \mathrm{~A}$. The mean change/year calculated for the 32 regions in each case is shown in Figure $2 B$. Since young cases of FAD are often thought to show a faster clinical course than older, possibly sporadic cases, it had been hypothesized that the young familial case would show a particularly steep rate of decline in LCMR. An inspection of Figures $2 \mathrm{~A}$ and $2 \mathrm{~B}$ makes it clear that this hypothesis was not upheld. There was no region in which this young case ranked 1 st, 2nd or 3rd among the AD group with regard to the rate of metabolic decline and only one (left orbital frontal) where he ranked 4th. Moreover, the average age of the 6 cases showing the highest rates of decline was slightly higher than the average age of the six showing the lower rates of decline. It may be worth noting, however, that an AD case who died 1 year after the second scan showed the greatest change of all.

The mean change/year in the 13 cases calculated for each region was found to vary considerably from region to region but, as indicated in Figure 3, showed a high degree of correlation with the difference in the logarithms of the normal and control group means (cf Figure 1): That is, those regions showing a particularly high normal:AD metabolic ratio were the same as those showing particularly large changes/year in the serial scans. These regions may therefore be taken as the ones showing the greatest metabolic sensitivity to Alzheimer-related changes. They included the midtemporal, inferior temporal, angular, 


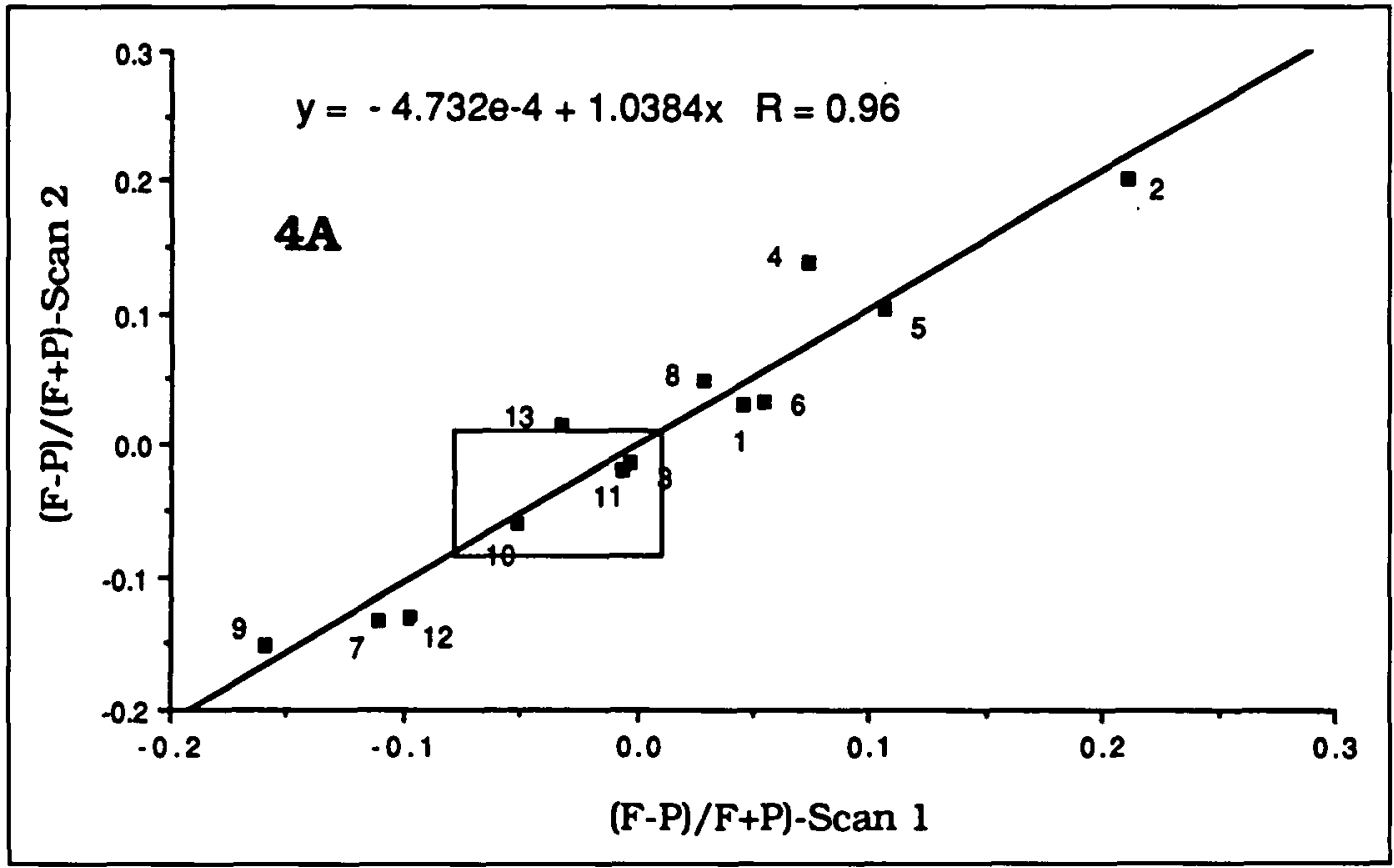

Figure 4:- Apparent stability of relative frontallparietal and frontalltemporal relationships over time in the serially scanned cases. The number by each point indicates the case as in Table 1. The rectangle indicates the mean \pm 2 $S . D$. for the single scans on 20 neurologically normal controls. As indicated in the text, the mean $(F-P) /(F+P)$ for this control group differed significantly from that calculated for the 57 AD cases given single scans; however. the mean $(F-T) /(F+T)$ for the controls was $0.055 \pm 0.030$, which was not significantly different from that for the $A D$ cases, $0.053 \pm 0.068, p=$ 0.87 . See methods for list of ROls used in calculating mean values for the frontal $(F)$, parietal $(P)$ and temporal (T) lobes. A) Individual $(F-P) /(F+P)$ values from scan 2 plotted against those from scan $l . B)$ Individual $(F-T) /(F+T)$ values from scan 2 plotted against those from scan 1 .

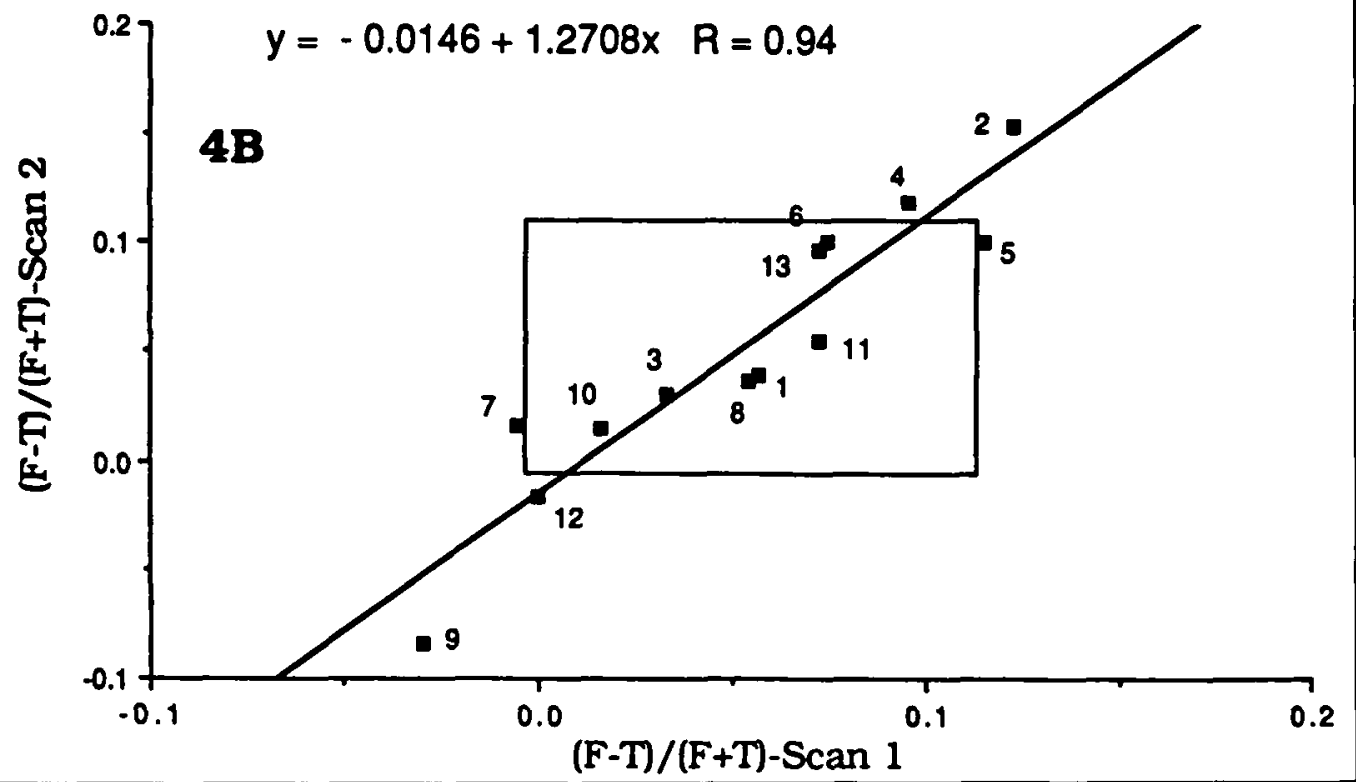

superior parietal and orbitofrontal gyri on both sides, as well as the superior temporal, medial temporal, midfrontal and supramarginal regions in the left hemisphere.

The mean values for the absolute asymmetry indices in the group of AD cases were significantly greater than those of the controls by ANOVA at $p<0.001$ in all regions except the caudate and putamen $(p<0.01)$ and cerebellum $(p<0.02)$. In the serial scan data, the Spearman correlation in the degree of regional asymmetry seen at scans 1 and 2 was very variable from case to case ( $r=0.24$ to $0.90 ; N=16)$ but was significant at $p<0.05$ in 9 of the 13 cases, including both cases confirmed at autopsy. In every case, the regions maintained their relative metabolic order very well (mean Spearman correlation coefficient $0.91 \pm 0.06$, range $0.76-0.96 ; \mathrm{N}=32$ ).

The mean $(F-P) /(F+P)$ for the $A D$ group $(0.012 \pm 0.101)$ was significantly higher than the mean for the control group
$(-0.038 \pm 0.02, p<0.03)$, but there was no significant difference in $(\mathrm{F}-\mathrm{T}) /(\mathrm{F}+\mathrm{T})$ (see caption to Figure 4$)$ and neither ratio in the control group was significantly affected by age. In the serially scanned group, there was excellent correlation between the ratios found at the first and second scans (Figure 4), as might be expected from the excellent stability in relative metabolic order. There were very small shifts $(0.05$ and $1.1 \%)$ to more negative values at the second scan, suggesting a slightly greater (but not significantly greater) relative involvement of the frontal lobes as the disease progressed.

\section{Correlations With Psychological Test Results}

As evident in Figure 2b, thé mean change per year in psychological test results did not correlate with the mean change/year in metabolic rate in the serially scanned cases. The correlation coefficient was still non-significant if the mean change/year in 
psychological test results in each case was expressed as a percent of the average psychological score for the case on first testing. The change in psychological test results did not correlate with the $(\mathrm{F}-\mathrm{P}) /(\mathrm{F}+\mathrm{P})$ or the $(\mathrm{F}-\mathrm{T}) /(\mathrm{F}+\mathrm{T})$ obtained on the first or second scan, or with the differences in these ratios between scans.

Extensive efforts were made, as outlined in the Methods section, to find significant correlations between the LCMR for individual regions and the psychological data. When so many correlations are sought, some will appear to be significant by chance alone. The number of non-significant correlations may have been inflated by comparing all psychological tests with all ROIs even in many cases where there was no theoretical reason to expect a significant relation. For example, there is no reason to expect a significant correlation between any measure of cortical functioning and cerebellar metabolism. Despite these problems, there was a pattern to the significant correlations which may be meaningful. In general, as indicated in Figure 5 and its footnotes:

1) Where significant correlations were found for results on a given psychological test, they tended to be with multiple cortical brain regions. As expected, there were relatively few significant correlations with scanning data for noncortical regions except in tests involving motor function (tapping and grip).

2) With only two exceptions, all significant correlations of psychological test data (or change/year in serial scans) with the Ln(LCMR) (or change/yr) for cortical regions were positive: i.e. the better the metabolic rate, the better the psychological performance.

3) The highest percentage of significant correlations was found when Spearman correlation coefficients were determined between the asymmetry index (AI) for each region and the psychological test scores. Again, however, all correlations for cortical regions were positive, indicating that the better the left:right cortical metabolic ratio, the better the performance on almost all psychological tests, including some non-verbal ones. The relatively few significant correlations with the Als for the caudate and putamen were also positive but the two significant correlations found with the cerebellar Als were negative; the signs of these correlations are consistent with the uncrossed and crossed diaschisis found, respectively, for the basal ganglia and cerebellum in PET scan data on a series of AD cases. 14

\section{Discussion}

There has been considerable controversy in the literature as to whether the LCMR in cortical regions declines with age in neurologically normal individuals. Our data are consistent with the conclusion expressed in a review by Frackowiak ${ }^{15}$ that the available evidence favors a small but significant decline in LCMR, (and in cerebral blood flow, but probably not in cerebral metabolic rate measured with oxygen). Yoshii et al ${ }^{16}$ reported FDG studies on 76 normal volunteers and found an age-related decline from a group of average age 33 to one of average age 67.2 ranging from $8.6 \%$ in the occipital region to $17.5 \%$ in the frontal region. The linear correlation equations from our control data would give declines across the same age change of $15.2 \%$ in the left SF, $17.1 \%$ in the right SF, $8 . \%$ in the left $\mathrm{mO}$ and $7.7 \%$ in the right $\mathrm{mO}$ region; these figures are clearly consistent with those of Yoshii et al ${ }^{16}$ who felt that much of the decline could be associated with brain atrophy. The lack of a correlation of $(\mathrm{F}-\mathrm{P}) /(\mathrm{F}+\mathrm{P})$ with age is inconsistent with the report of deLeon et al 17 who found a reduction in the frontal/parietal ratio with age.

Yoshii et al ${ }^{16}$ also found that the cerebral metabolic rate for glucose was significantly higher in females than in males. This is consistent with the report of higher cerebral blood flow in females. ${ }^{18} \mathrm{We}$, like Tyler et al, ${ }^{19}$ found no difference between sexes but this may be related to the smaller size of control groups as compared with that used by Yoshii et al.

As expected from previous literature, 1,11 the cortical LCMR(s) in AD were significantly less than in age-matched controls, while the hemispheric asymmetries in all regions studied were significantly greater. ${ }^{12,14,20,21}$ A small difference between our findings and that in some of the literature is that the deficiencies in AD did not appear to be as limited to the parietal/temporal vs frontal regions. This is evident particularly in the lack of significant difference between the AD and control groups in the ratio $(\mathrm{F}-\mathrm{T}) /(\mathrm{F}+\mathrm{T})$, and in the distribution of this ratio in the serially scanned group as compared to control means (Figure 4b). However, the parietal region does appear to be more involved than the frontal, as evidenced by the significantly higher value for $(\mathrm{F}-\mathrm{P}) /(\mathrm{F}+\mathrm{P})$ found for the $A D$ as compared to the control group, and by the distribution of this ratio in the serially scanned group indicated in Figure $4 \mathrm{a}$. The significant difference in $(\mathrm{F}-\mathrm{P}) /(\mathrm{F}+\mathrm{P})$ between $\mathrm{AD}$ and control groups is in accord with the data of Jagust et al ${ }^{12}$ and Haxby et al, ${ }^{20}$ although the decrease in ratio between serial scans is smaller than might be expected from those reports.

In repeat PET scans on a normal volunteer at an approximate 1-year interval (data not shown), we found only about a $3 \%$ change in the average cerebral metabolic rate, although some individual regions showed variations up to $10 \%$. In studies on groups of individuals, Cutler et al 22 reported metabolic changes of $\leq 11-12 \%$ in FDG scans 1 to 2 years apart and Lenzi et al 23 reported similar stability in controls on measurements of cerebral blood flow or $\mathrm{O}_{2}$ metabolism. Others ${ }^{19,24}$ have shown good stability of the LCMR over a short (1-2 day) interval in groups of normal individuals. Such studies suggest that comparison of longitudinal changes in AD patients with cross-sectional data on normal controls, as done in Figure 2, are probably valid.

All groups doing serial scans on AD cases have found more drastic decreases in LCMR over time in most cases than would be expected from the available control data - whether these be from the numerous cross-sectional or the limited number of serial studies. $12,20,22.25-27$ Our findings are in agreement with this literature (Figure 3 ). The change in $\operatorname{Ln}(\mathrm{LCMR})$ seemed to be surprisingly widespread since the Spearman correlation coefficient between the $\operatorname{Ln}(\mathrm{LCMR}) \mathrm{s}$ for the first and second scan in each case was highly significant. On the other hand, the metabolic asymmetries were not stable over time in all brain regions. This agrees with the study of Jagust et al 12 but not with the reports of Grady et $\mathrm{al}^{25}$ and Haxby et al.20 A change in metabolic asymmetry over time may reflect the progress and spread of pathology.

Two points appear of particular interest in the serial scan 


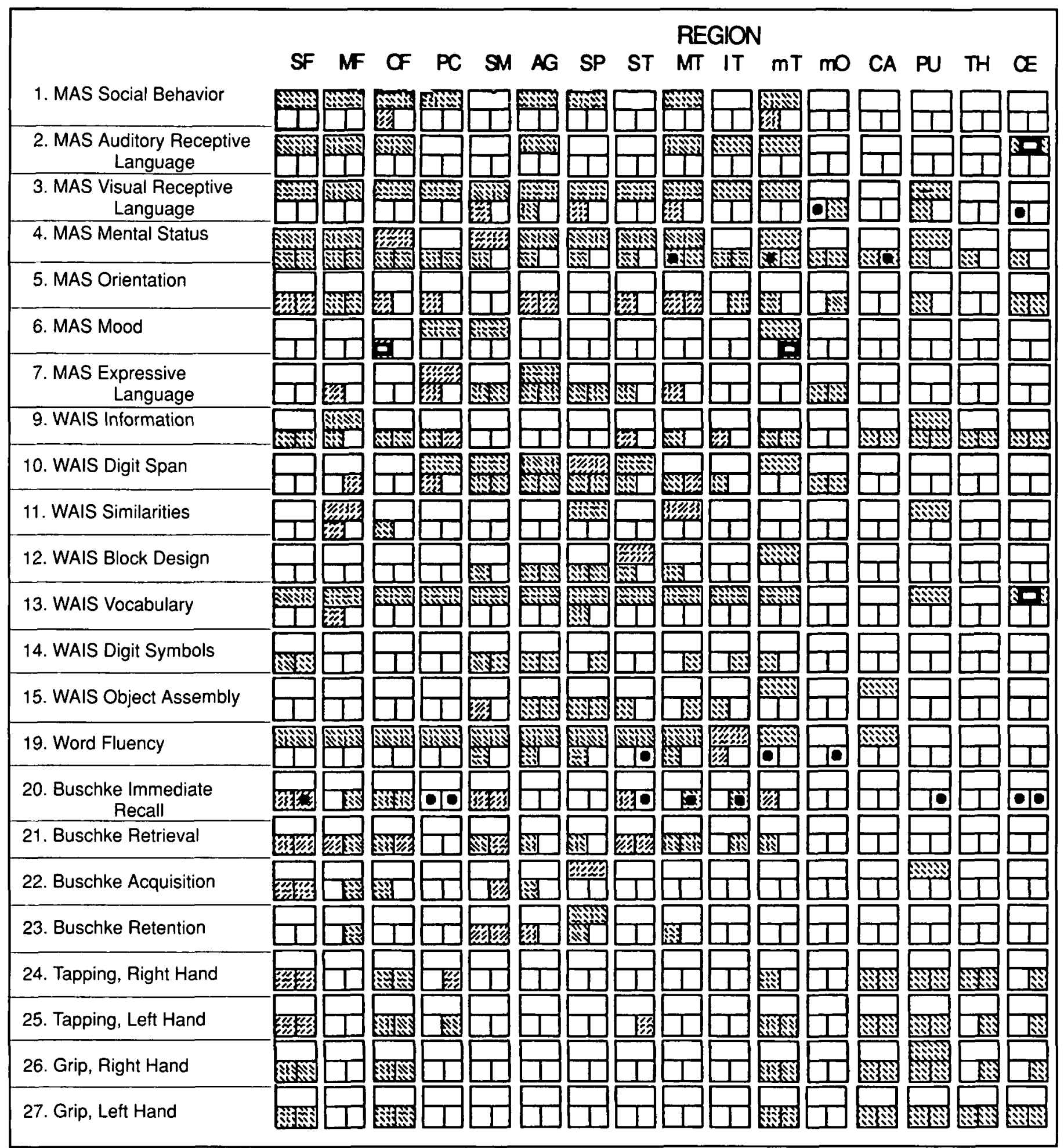

A

data. First, the relatively young case of familial AD did not show a particularly high rate of metabolic loss when compared with the older serially scanned cases. This was contrary to our expectation, which was based upon the widely held clinical view that the disease generally progresses faster in younger cases. Cutler et al 22 reported 3 serial assessments, done at 8 month intervals, on a 57-year-old man with early dementia and a family history of Alzheimer's disease. The patient, however, was still alive and hence had not been pathologically confirmed. They commented that the metabolic changes found in this patient were two- or three-times greater than the normal variability over time in controls. The data they reported, calculated as for Figure 3, would yield an average rate of decrease in $\mathrm{Ln}(\mathrm{LCMR}) / \mathrm{yr}$ of $0.30 \pm 0.225$ between scans 1 and 2 , and 0.011 


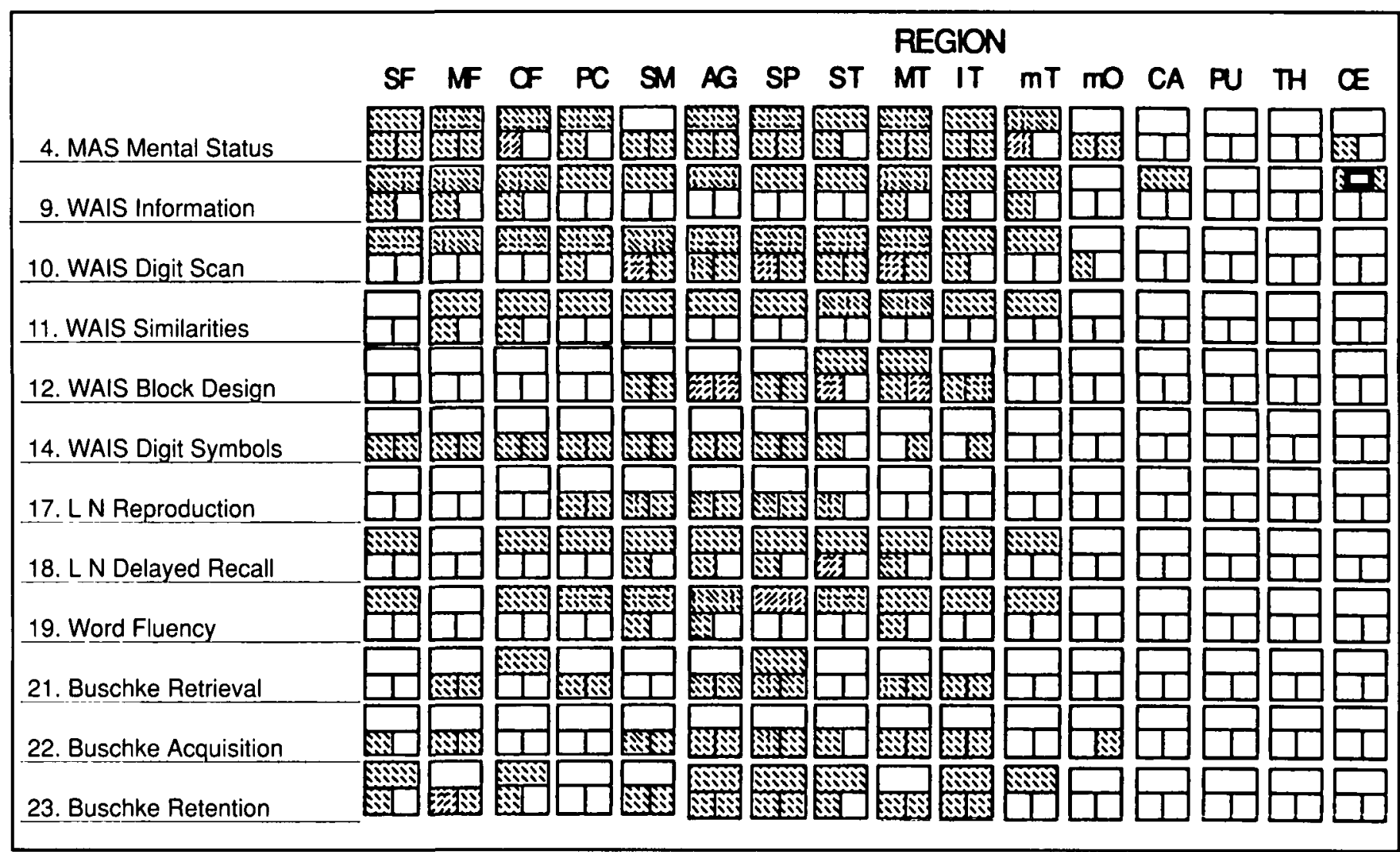

B

Figure 5:- Summary of significant Spearman correlations found between psychological test results and PET FDG data. The rectangular box ( G5) is used to indicate the significance of the correlation between psychological test data and the asymmetry index for the region as outlined under Methods, while the 国 squares record correlations with the $\operatorname{Ln}(L C M R)$ for that ROI in the left and right hemispheres. ROI abbreviations are as in Figure 1. Shading indicates a significant correlation at $p<0.05$. All correlations were positive except as indicated by a black bar, as e.g. Data are not given for psychological test 16 (Luria Nebraska immediate recall) because all correlations with the Al and the individual Ln(LCMR)s were not significant. The change in this test over time in the group with repeat scans, however, appeared to correlate signficanty with the change in metabolic rate in 7 regions (ROF, LPC, RST, RMT, RIT, LmO and RPU). A) Data from a group of 13 presumed AD cases having repeat scans $A-$ in the box indicates the rate of change in metabolic rate from scan to scan showed a significamt $(p<0.05)$ Spearman correlation with the rate of change in the psychological tests; all such correlations were also positive. Data are not given for psychological tests 18 (LN delayed recall), 17 ( $L N$ reproduction) or 8 (MAS accessibility) because there were, respectively, only one (in LTT), wo (RMT and LmO) or three (LOF, LST and LPU) significant correlations. B) Data from a group of 57 AD cases having single scans. Data for many of the psychological tests (i.e. \#1-3, 5-8, 13, 15, 24-27) were not available for this group and data for tests 16 (LN Immediate Recall) and 20 (Busche Immediate Recall) are not given because there were no significant correlations.

\pm 0.016 between scans 2 and 3 . The first value approximates the highest rate of loss seen in any of our serially scanned patients, while the second is surprisingly small. Interestingly, the case reported by Cutler et al also seemed to be relatively stable on psychological examination between scans 2 and 3. In general, however, our results suggest the FAD case is similar to the other cases studied except for the age of onset and the relative preservation of LCMR in the cerebellum, thalamus and striatum (cf Figures $1 \mathrm{~A}$ and $1 \mathrm{~B}$ ).

A second point of interest from the serial scan data is that, although the various regions retained a stable metabolic rank order in each individual, the average decrement/yr varied more than three-fold between regions, and the ROIs showing the most serious decrements between scans were the same as those showing the largest abnormalities in comparisons of $\mathrm{AD}$ and control groups (Figure 3 ). One might have hypothesized that the regions showing particularly large decrements would be those that were relatively unaffected in early stages but became involved as the disease spread; our data clearly do not support this hypothesis but are rather consistent with the alternative hypothesis that specific cortical regions are especially sensitive to Alzheimer's disease.

In the literature on FDG scans in dementia, there is general, $1,10,28$ although not complete, ${ }^{29}$ agreement that severely demented individuals as a group show more severe metabolic deficits than do mildly affected cases. However, attempts at more exact correlations between psychological test performance and LCMR(s) obtained under resting conditions have been largely unsuccessful. ${ }^{2}$ Serial scans on individuals would appear to offer a possible way of minimizing intra-subject variability and thus offer a better approach to such correlations. However, the available literature suggests that, even in such serial studies, correlations have been difficult. $12,20,22,25-27,30$

One of the more frequently reported findings is that meta- 
bolic asymmetry can be correlated with psychological asymmetry, i.e. those patients having greater defects in verbal as compared to visual tasks might have greater metabolic defects in the left hemisphere, and vice versa. 29,31 This suggested that the asymmetry index in selected cortical regions might be negatively correlated with results in some psychological tasks and positively correlated with others. This proved not to be the case; all such significant correlations were positive, indicating the importance of left hemisphere metabolism ( $\mathrm{cf}^{12}$ ).

In the serial scan data, the average change in psychological test score for each case was not correlated with many PET scan variables tested. In particular, the change in psychological test score did not correlate significantly with the change in $(\mathrm{F}-\mathrm{P}) /(\mathrm{F}+\mathrm{P})$ between scans although a significant relationship was expected from the report of Jagust et al 12 on serially scanned AD cases.

The multiple nature of the correlations found between the results in many psychological tests and cortical $\mathrm{Ln}(\mathrm{LCMR}) \mathrm{s}$ suggests to us that: (1) performance on a given test may depend primarily on one cortical region but multiple correlations appear significant because the metabolic deficiency is increasing in a large number of regions at very similar rates; (2) each psychological task involves a network of cortical regions, and metabolic deficiency in any one can contribute to defective performance of such a task; and/or (3) the primary and early problem in $\mathrm{AD}$ is loss of hippocampal neurons serving short-term memory and the effect of progressive deterioration in this region, not studied in most PET work, on psychological test performance outweighs any concurrent cortical degenerative processes that may be occurring in the disease. We believe the second and third possibilities may be of particular importance.

It has been observed that the general pattern of metabolic deficits in clinically diagnosed $A D$ cases is very close to the pattern of neuronal loss and of plaque and tangle formation seen in the cortex in autopsied AD brains. ${ }^{32}$ In PET-scanned cases that have come to autopsy, we have observed good correlation between regional metabolic deficiencies and cortical neuronal $\operatorname{loss}^{33}$ (and unpublished observations). Thus, despite the inability to develop meaningful correlations between changes in LCMR, revealed in serial PET scans under resting conditions, and clinical progression, as indicated by psychological testing, we believe continued serial scanning of AD patients will give useful data on the regional rates of neuronal loss during progression of the disease.

\section{ACKNOWLEDGEMENTS}

This work was supported by grants from the Medical Research Council of Canada and the Alzheimer Society of British Columbia. The authors thank Ms. M. Druhan, Dr. M.J. Adam, Dr. W. Ammann, Dr. J.G. Rogers, Dr. T.L. Ruth, Dr. B.D. Pate, Ms. P. Schofield and Dr. W.R.W. Martin for their assistance.

\section{REFERENCES}

1. McGeer PL. Brain imaging in Alzheimer's disease. Br Med Bull 1986; 42: 24-28.

2. Parks RW, Crockett DJ, McGeer PL. Systems model of cortical organization: positron emission tomography and neuropsychological test performance. Arch Clin Neuropsych 1989; 4: (in press).

3. McKhann G, Drachman D, Folstein M, et al. Clinical diagnosis of Alzheimer's disease: Report of the NINCDS-ADRDA work group under the auspices of Department of Health and Human
Services task force on Alzheimer's disease. Neurology 1984; 34 : 939-944.

4. Sadovnick AD, Tuokko H, Horton A, et al. Familial Alzheimer's disease. Can J Neurol Sci 1989; 15: 142-146.

5. Crockett D, Tuokko H, Koch W, et al. The assessment of everyday functioning using the present functioning questionaire and the functional rating scale in elderly samples. Clin Gerontol 1989; 8: 3-25.

6. Tuokko H, Crockett $\mathrm{D}$. Cued recall and memory disorders in dementia. J Clin Exp Neuropsychol 1989; 11: 278-294.

7. Martin WRW, Beckman JH, Calne DB, et al. Cerebral glucose metabolism in Parkinson's disease. Can J Neurol Sci 1984; 1: 169-173.

8. Hanaway J, Scott WR, Strother CM. Atlas of the human brain and the orbit for computed tomography. St. Louis: WH Green 1980.

9. Phelps ME, Huang SC, Hoffman EJ, et al. Tomographic measurement of local cerebral glucose metabolic rate in humans with (F-18)2-fluoro-2-deoxy-D-glucose: validation of method. Ann Neurol 1979; 6: 371-388.

10. McGeer PL, Kamo H, Harrop R, et al. Positron emission tomography in patients with clinically diagnosed Alzheimer's disease. Can Med Assoc J 1986; 134: 597-607.

11. Haxby JV, Rapoport SI. Abnormalities of regional brain metabolism in Alzheimer's disease and their relation to functional impairment. Prog Neuro-Psychopharmacol \& Biol Psychiatry 1986; 10: 427-438.

12. Jagust WJ, Friedland RP, Budinger TF, et al. Longitudinal studies of regional cerebral metabolism in Alzheimer's disease. Neurology 1988; 38: 909-912.

13. Coval M, Crockett D, Holliday S, et al. A multi-focus assessment scale for use with frail elderly populations. Can J Aging 1985; 4: 101-109.

14. Akiyama H, Harrop R, McGeer PL, et al. Crossed cerebellar and uncrossed basal ganglia and thalamic diaschisis in Alzheimer's disease. Neurology 1989; 39: 541-548.

15. Frackowiak RSJ. Cerebral energy metabolism and blood flow in normal human ageing: a short review. Circulation et Metabolism du Cerveau 1987; 4: 87-92.

16. Yoshii F, Barker WW, Chang JY, et al. Sensitivity of cerebral glucose metabolism to age, gender, brain volume, brain atrophy, and cerebrovascular risk factors. J Cereb Blood Flow Metabol 1988; 8: 654-661.

17. deLeon MJ, George AE, Tomanelli J, et al. Positron emission tomography studies of normal aging: a replication of PET III and 18-FDG using PET VI and 11-CDG. Neurobiol Aging 1987; 8: 319-323.

18. Rodriguez G, Warkentin S, Risberg J, et al. Sex differences in regional cerebral blood flow. J Cereb Blood Flow Metabol 1988; 8: 783-789.

19. Tyler JL, Strother SC, Zatorre RJ, et al. Stability of regional glucose metabolism in the normal brain measured by positron emission tomography. J Nucl Med 1988; 29: 631-642.

20. Haxby JV, Grady CL, Koss E, et al. Longitudinal study of brain metabolic and neuropsychological heterogeneity in dementia of the Alzheimer type: evidence for subtypes. J Cereb Blood Flow Metabol 1988; 7 (Suppl 1): S377.

21. Friedland RP, Budinger TF, Koss E, et al. Alzheimer's disease: anterior-posterior and lateral hemispheric alterations in cortical glucose utilization. Neurosci Lett 1985; 53: 235-240.

22. Cutler NR, Haxby JV, Duara R, et al. Brain metabolism as measured with positron emission tomography: serial assessment in a patient with familial Alzheimer's disease. Neurology 1985; 35: 1556-1561.

23. Lenzi GL, Gibbs JM, Frackowiak RSJ, et al. Measurement of cerebral blood flow and oxygen metabolism by positron emission tomography and the ${ }^{15} \mathrm{O}$ steady-state technique: aspects of methodology, reproducibility and clinical application. In: Magistretti PL, ed. Functional Radionuclide Imaging of the Brain, New York, Raven Press, 1983; 291-309.

24. Bartlett EJ, Brodie JD, Wolf AP, et al. Reproducibility of cerebral glucose metabolic measurements in resting human subjects. J Cereb Blood Flow Metabol 1988; 8: 502-512. 
25. Grady CL, Haxby JV, Schlageter NL, et al. Stability of metabolic and neuropsychological asymmetries in dementia of the Alzheimer type. Neurology 1986; 36: 1390-1392.

26. Grady CL, Haxby JV, Horwitz B, et al. Longitudinal study of the early neuropsychological and cerebral metabolic changes in dementia of the Alzheimer type. J Clin Exp Neuropsychol 1988; 10: 576-596.

27. Szelies B, Herholz K, Pawlik G, et al. Cerebral glucose metabolism in presenile dementia (Alzheimer's disease) - follow-up under treatment course with a muscarinic choline agonist. Fortschr Neurol Psychiatry 1986; 54: 364-373.

28. Jamieson DG, Chawluk JB, Alavi A, et al. The effect of disease severity on local cerebral glucose metabolism in Alzheimer's disease. J Cereb Blood Flow Metabol 1987; 7 (Suppl 1): S410.

29. Friedland RP, Jagust WJ, Budinger TF, et al. Consistency of temporal-parietal cortex hypometabolism in probable Alzheimer's disease (AD): relationship to cognitive decline. J Cereb Blood Flow Metabol 1987; 7 (Suppl 1): S403.

30. Duara R, Grady C, Haxby J, et al. Positron emission tomography in Alzheimer's disease. Neurology 1986; 36: 879-887.

31. Loewenstein D, Yoshii F, Barker WW, et al. Predominant left hemisphere metabolic deficit predicts early manifestation of dementia. J Cereb Blood Flow Metabol 1987; 7 (Suppl 1): S416.

32. Friedland RP, Brun A, Budinger TF. Pathological and positron emission tomography correlations in Alzheimer's disease. Lancet 1985i: 228.

33. McGeer PL, Kamo H, Harrop R, et al. Comparison of PET, MRI and CT with pathology in a proven case of Alzheimer's disease. Neurology 1986; 36: 1569-1574. 